\title{
DR. JAGDISH PARIKH: MANAGERS DO NOT ENJOY THEIR LIVES AND WORK
}

\author{
Dr. Jagdish Parikh is the Founder and President of the Centre for Executive Renewal (Switzer- \\ land), the Chairman of A. L. Movers Pvt. Ltd. (Allied Lemuir) and author of the book "Managing \\ Your Self: Management by Detached Involvement". In his exclusive interview for Central Europe- \\ an Business Review, Dr. Parikh talks about today's economic system, the frustration of managers \\ and about how one can get a richer life.
}

Your big topic is joy in our lives. As you are talking to top-level managers all over the world, do they enjoy their lives, their work?

The answer is simple: No, they don't. This is because the whole system is faulty. There are two axes of human behavior. One is the value axis; the other is the ideology axis. The value axis varies from spirituality to materialism. And on the ideology axis there's communism and capitalism. It's a nice thing to have all these in a synthesis because the ideology aims at the community and spirituality aims at individuals. Unfortunately, what has happened is that spirituality degenerated into religion. And religion is based on what people believe in, on fate. It's unfortunate that preachers have not been spiritual themselves and therefore their preaching isn't inclusive but the opposite - it's exclusive. This causes people to think that one religion is better than other religions. Religions are supposed to unite, but the bloodiest of all wars in human history were religious. And the same thing is happening today the world is getting divided between Islam and the rest of the world. Religions are great but they are not being taught properly - preachers and interpreters are not sincere and honest in their jobs. On the other hand, materialism is another extreme. Materialism becomes a kind of attachment, an identity. And it leads us to very adversarial competition so everybody feels insecure and afraid. So this is the position of those two parameters. As far as ideologies are concerned - communism has failed and capitalism has also failed. Communism became a common society and capitalism has become a conflicting society.
All four parameters are having some problems. So how do we get out of this? What is the solution to this problem?

I think the synthesis of those parameters is the answer, not compromising between them. Because even the various ideologies like different shades of socialism that we tried have fallen between these two stools. All kinds of things have happened and there are all kinds of frustrations, because earlier, people were able to find strong reasons to use this or that ideology but now, people are beginning to feel confused; what is the right strategy? Being a business man, I obviously think about the economy, the economic system. What is the problem in there? We have crisis after crisis, particularly in the financial field. Nothing wrong with the system but within the system because the system allows one to misbehave.

\section{Why is it becoming like that?}

The goal of today's economic system is creating an affluent society. What happens now is that corporations support a certain economy and they have to keep on expanding and growing. And by growth I mean quantity growth, not only financial growth - the more, the better. The strategies, the missions, the visions of the organizations and corporations are oriented to expansion and I would say it is a very dangerous thing. What happens is that this kind of management practices, management theories and management education is creating this kind of individual managers. Today's managers are oriented towards organizations' objectives, which are all trying 
to achieve an affluent society. The system's objective is an affluent society, organizational growth, managers with competencies and skills, but what happens to the poor individual? You and I and the others are under constant pressure. We are the victims of the system of never-ending work. In other words, unless we keep on growing because of inflation and many other things, we will not progress, and progress means having material comforts.

\section{Are there really any people who are interested in not in having more but having just enough?}

Very few. Because what happens is that every individual is obviously sensitive to what others think of him or her. And in this kind of environment, they might actually end up being blamed for not being interested in progress or in other words, for indulging an undesirable quality of life in a way. Most people wouldn't understand the idea of having just enough because they internalize that having and doing more is always better. And therefore, it is this system that is primarily responsible for the situation at hand. So how do we change it? I say switch it off. Affluent society is the goal of the current society. Life-enriching society should be the goal of the future society. And how do you get a richer life? You focus on the individual. Not on the global situation or the corporal situation but on the individual. And when the focus is there and the right kind of habits and knowledge are given to the individual, organizations will facilitate the development of the manager and therefore development of the corporation not by squeezing the manager but by enhancing the individual, making organizations learning systems, not just producers of goods and services. And that leads to a life-enriching society.

\section{How do we get there?}

(Laughs) If I knew that, I'd be the president of the United Nations! But the way leads through the individual because individuals lead the organizations. So, the starting point is the individual and the first thing that needs to be sorted out is the educational system so that it begins to impart these kinds of values to individuals and also explains that the final criteria are not just the bottom line with all the monitoring and calculations. In my opinion, there should be three sets of criteria, not just economic or financial but also ethical-ecological and the third one would be techno-economical or psychosocial. So, the corporate progress should be judged by these three sets criteria. And then, gradually, it'll become a life-enriching organization.

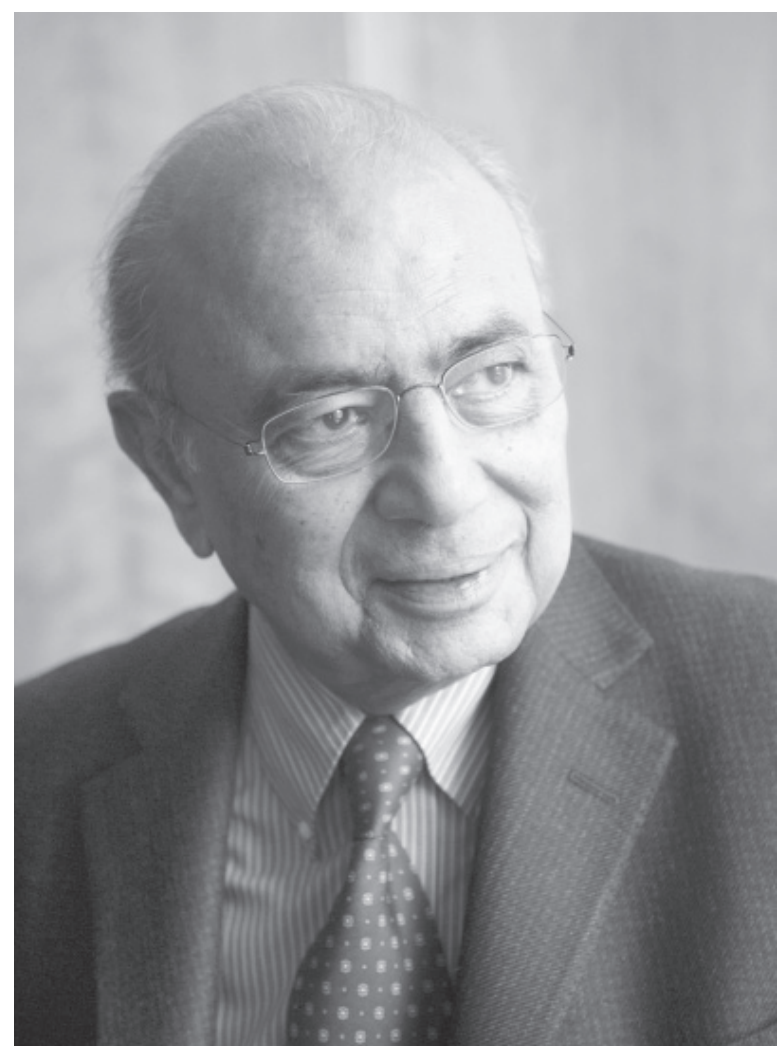

Photo: Jan Branč

\section{As you travel a lot, have you seen any regions where this is likely to happen?}

Frankly, when I meet with people, the general expression is frustration and helplessness with being the victim of where the world is going. Take, for instance, global warming - people are talking at conferences on international, national and regional levels but in the end, nobody does anything.

\section{Do you think that there's some kind of potential in India?}

Yes. I'm very much an optimist because the basic wealth, which is the culture, is still there. The only thing is that it has to be disseminated. I'm an optimist, so I remain positive but some of the others are pessimistic because of globalization. Western culture is taking over the old traditional culture because many of the people who work in powerful positions in business and government have been educated in the USA or in western countries in general. As for globalization, the context should be global but what you see is that there's Coca Cola culture, Mac Notebook culture, and the culture of wearing jeans spreading and in the end, the youngsters in India 
are no different from the youngsters here in London or the USA.

I know that from your perspective, the Central European region must seem very tiny but is there something specific about it? And what would your advice for people from this region be so that they are more successful?

I have taught in several Central European countries and the positive thing is that people from this region have still maintained a certain amount of open-mindedness. They were functioning under a very different system for years and are now facing a transition from communism to capitalism but they should be careful because as I was saying, both these system have failed. But my general impression is that you people have openness and curiosity. Just the fact that you are asking this question shows a difference between here and the western countries. Because there, people think that the way they are doing things is the right way to do them and therefore are not that open-minded anymore.

\section{Author}

Tomáš Poucha Marketing Institute Faculty of Business Administration University of Economics, Prague Nám. W. Churchilla 4, 13067

Prague 3, Czech Republic tpoucha@mkti.cz 